Results: Knee OA progression (form radiographic stage II to stage III) within 1 year follow up was documented in 15 patients (Group 2 - with progressed $\mathrm{OA}$ ), while 170 patients did not show any progression (Group 1 - no progression). Both groups were comparable in terms of age, age at RA onset, and duration of the disease. Although patients who progressed had higher body weight $(97,1 \pm 14,0$ vs $74,2 \pm 10,8 \mathrm{~kg}, \mathrm{p}<0,0001)$ and $\operatorname{BMl}\left(31,9 \pm 5,8\right.$ vs $\left.27,3 \pm 4,1 \mathrm{~kg} / \mathrm{m}^{2}, \mathrm{p}<0,0001\right)$. Patients from Group II had more intense knee pain during walking (VAS - $65,8 \pm 11,8$ vs 47,5 $\pm 18,7 \mathrm{~mm}(p<0,0003)$, and higher WOMAC: pain- $330,5 \pm 66,0$ vs 237,8 $\pm 85,4 \mathrm{~mm}, \quad \mathrm{p}<0,0001$; function - $1044 \pm 190,4$ vs $859,8 \pm 243,8 \mathrm{~mm}$, $\mathrm{p}<0,007$. Patients from Group II showed higher rates of varus knee alignment $(66,7 \%$ vs $35,3 \%, R R=1,89,95 \% \mathrm{Cl} 1,25-2,85, p=0,02)$ and H.valgus $(86,7 \%$ vs $61,8 \%, R R=1,4,95 \% \mathrm{Cl} 1,11-1,77, p=0,04)$, as well as higher rates of arterial hypertension $(93,3 \%$ vs $71,8 \%$, respectively, $\mathrm{RR}=1,3,95 \% \mathrm{Cl} 1,1-1,53, \mathrm{p}=0,05)$ and type 2 diabetes mellitus (DM) (33,3\% vs 12,9\%, RR=2,57, 95\% Cl 1,14-5,82, $p=0,04)$. MRI showed higher percentage of medial and lateral tibia cartilage defects in Group 2 patients $(57,2 \%$ vs $18,6 \%$, respectively; $R R=3,06,95 \% \mathrm{Cl} 1,74-5,38$, $\mathrm{p}<0,003 ; 57,2 \%$ vs $14 \%, \mathrm{RR}=4,08,95 \%$ Cl 2,23-7,46 $\mathrm{p}<0,0006)$; bone marrow edema (BME) in medial $(71,4 \%$ vs $12,2 \%, R R=5,83,95 \% \quad C l$ $3,38-10,1, p<0,000004)$ and lateral tibial compartments $(21,4 \%$ vs $4,1 \%$, $\mathrm{RR}=5,25,95 \% \mathrm{Cl} 1,47-18,7, \mathrm{p}=0,03$ ); subchondral cysts, occupying more than $25 \%$ of the area in medial and lateral tibial compartments (respectively, $28,6 \%$ vs $7,4 \%, R R=3,84,95 \% \mathrm{Cl} 1,4-10,5, \mathrm{p}<0,03$; and $35,7 \%$ vs $8,8 \%, R R=4,06,95 \%$ Cl 1,7-9,7, $p=0,01$ ). Synovitis (MRI findings) was documented in $100 \%$ patients from Group 2 and in $58,4 \%$ patients without $\mathrm{OA}$ progression ( $\mathrm{RR}=1,71,95 \% \mathrm{Cl} 1,5-2,0, \mathrm{p}=0,002)$. A multivariate (discriminant) analysis showed that the most important risk factors for knee OA progression were: higher body weight, high WOMAC pain score, presence of type $2 \mathrm{DM}$, BME in medial tibial compartment, and cartilage damage in medial tibial compartment (MRI findings). A model capable of predicting rapid progression of knee $\mathrm{OA}$ in an individual patient with high accuracy (area under the ROC-curve $0,925(95 \% \mathrm{Cl} 0,828-1,022)$ ) has been developed based on identified RF and their coefficients.

\begin{tabular}{|l|l|l|}
\hline \multicolumn{1}{|c|}{ Factors } & \multicolumn{1}{c|}{$\begin{array}{c}\text { Discriminant } \\
\text { function } \\
\text { coefficients }\end{array}$} \\
\hline Body weight, $\mathrm{kg}$ & 0,1698 \\
\hline Pain WOMAC, mm & 0,0068 \\
\hline DM type 2 & 1,8387 \\
\hline BME in medial tibia & 1,1848 \\
\hline $\begin{array}{l}\text { Cartilage destruction in the } \\
\text { medial tibial compartment }\end{array}$ & 0,4724 & \\
\hline Constant & 21,6615 & \\
\hline
\end{tabular}

Abstract THU0459 - Figure 1

Conclusion: In a prospective multicenter study, using comprehensive instrumental examination the following key predictors of rapid knee OA progression were identified: excessive body weight, high WOMAC pain score, presence of type $2 \mathrm{DM}$, BME in medial tibial compartment, and cartilage damage in medial tibial compartment (MRI findings).

Disclosure of Interests: Elena Taskina Speakers bureau: Bayer, Sandoz, Boeringer-ingelheim, Ludmila Alekseeva Speakers bureau: Bayer, Boeringer-ingelheim, Gedeon-Richter, Servier, Natalia Kashevarova: None declared, Sergey Anikin: None declared, Evgenia Sharapova: None declared, Ekaterina Strebkova: None declared, Lena Zonova Speakers bureau: Sandoz, Pfizer, Abbvie, Novartis, Bayer, Tatiana Raskina: None declared, Elvira Otteva Speakers bureau: Pfizer, Abbvie, Novartis, Irina Vinogradova Speakers bureau: Pfizer, MSD, Aleksandr Lila Speakers bureau: Sandoz, Pfizer, Abbvie, Novartis, Bayer

DOI: 10.1136/annrheumdis-2019-eular.4525

\section{THU0460 IDENTIFICATION OF POSTOPERATIVE PAIN BIOMARKERS USING GENE EXPRESSION ANALYSES IN THE PERIPHERAL BLOOD OF OSTEOARTHRITIC PATIENTS PRIOR TO JOINT REPLACEMENT}

Elena Tchetina ${ }^{1}$, Kseniya Glemba ${ }^{2}$, Sergey Makarov ${ }^{2} .{ }^{1}$ Nasonova Research Institute of Rheumatology, Immunology and Molecular Biology, Moscow, Russian Federation; ${ }^{2}$ Nasonova Research Institute of Rheumatology, Rheumoorthopaedic, Moscow, Russian Federation

Background: Osteoarthritis $(O A)$ is a chronic rheumatic disease, which involves pain, limited inflammation and local destruction of the knee joint.
OA pain is a major clinical symptom, which limits working capacity and denotes an important indication for joint replacement in the end-stage OA. In spite of significant number of positive outcomes, chronic postoperative pain represents a major adverse consequence of surgery, which is observed in $10-40 \%$ of OA patients. Therefore, identification of patients potentially capable of developing chronic postoperative pain prior to surgery could significantly improve therapy outcome. Central sensitization is in charge of pain symptoms in about $30 \%$ of end-stage OA patients. Several recently identified molecular markers such as cytokines, chemokines, calcium and glutamate transporters, caspases, and proteases has been shown to be responsible for central sensitization. Therefore, we hypothesized that genes related to pain sensitization whose expression is upregulated in about $30 \%$ of the examined end-stage OA patient cohort might be responsible for postoperative pain.

Objectives: To outline an approach for search of biomarkers related to chronic postoperative pain development before joint replacement in the peripheral blood of end-stage OA patients.

Methods: We examined peripheral blood of 26 healthy volunteers (aver age age $55 \pm 8.3$ years old) and 53 end-stage OA patients (average age $56.5 \pm 8.9$ years old) undergoing joint replacement surgery. MMP-9, TIMP1, TGF $\beta 1$, and caspase 3 protein levels were quantified by ELISA. Total RNA isolated from whole blood was used in expression studies for the genes related to central sensitization such as mechanistic target of rapamycin, mTOR; caspase 3; metalloproteinase (MMP)-9; tissue inhibitor of metalloproteinase TIMP1; cathepsins $\mathrm{K}$ and $\mathrm{S}$; interleukin (IL)-1 $\beta$; cyclooxygenase $(\mathrm{COX}) 2$; tumor necrosis factor $(\mathrm{TNF}) \alpha$, and transforming growth (TGF) 31 . These were performed with quantitative real-time RT-PCR.

Results: Retrospective analysis of gene expression in the peripheral blood of end-stage OA patients before joint replacement surgery revealed that gene expression data for TNF $\alpha$, IL-1 $\beta$, COX2, TGF $\beta 1$, and mTOR were not applicable as these gene expressions were significantly higher compared to healthy controls in all the examined $\mathrm{OA}$ patients. High expres sion of pain associated cathepsin $S$ in $17 \%$ of the examined OA patients and cathepsin $\mathrm{K}$, in $21 \%$ might indicate the possibility of postoperative pain development in these OA patients. In contrast, low expression of caspase 3 in $43 \%$ of the examined OA patients and MMP-9, in $23 \%$, might point toward the absence of postoperative pain in these subjects. Conclusion: Gene expression analysis in the peripheral blood of the end stage OA patients measured before joint replacement surgery might represent an approach for prediction of postoperative pain development.

Disclosure of Interests: : None declared DOI: 10.1136/annrheumdis-2019-eular.5313

\section{THU0461 IDENTIFICATION OF DEFINITIONS OF POOR OUTCOME AFTER TREATMENT OF KNEE OSTEOARTHRITIS: A LITERATURE REVIEW}

Malou te Molder ${ }^{1}$, J.M.H. Smolders ${ }^{2}$, Petra Heesterbeek ${ }^{3}$, Cornelia van den Ende ${ }^{4}$ ${ }^{1}$ Sint Maartenskliniek, Research, Nijmegen, Netherlands; ${ }^{2}$ Sint Maartenskliniek, Orthopaedic Surgery, Nijmegen, Netherlands; ${ }^{3}$ Sint Maartenskliniek, Orthopaedic Research, Nijmegen, Netherlands; ${ }^{4}$ Sint Maartenskliniek, Rheumatology Research, Nijmegen, Netherlands

Background: Total knee replacement (TKR) is considered an effective intervention of the treatment of advanced knee osteoarthritis (OA) (Kellgren \& Lawrence >2). However, a significant proportion of patients could be considered as a poor-responder to TKR (i.e. no or little improvement) in terms of chronic knee pain, functional disability, poor quality of life (QoL), and dissatisfaction after TKR. Both in research and in clinical practice it is challenging to identify those patients with an unfavourable course after TKR. It is difficult though to quantify the proportion of patients with poor response to TKR, as different definitions of, and perspectives (clinician's and patient's) on failure are being used.

Objectives: The aim of this study was to review the literature and summarize definitions of poor response to TKR.

Methods: A systematic search up to 2016 was performed to identify and review previously used definitions of poor response to primary TKR in the literature. Studies were included if dichotomous definitions of outcome after primary TKR were used, if a prospective design was used and in English full text available. The type, amount and combination of domains (i.e. pain and physical function), outcome measures, type of responses (absolute/relative, change/cut-off), values and moments of follow-up used in definitions were summarized.

Results: A total of 44 different dichotomous definitions of poor response to TKR, were extracted from 1849 initially identified studies. 34 definitions incorporated one domain, six definitions comprised two domains and four definitions comprised three domains. Eight different domains were used in identified definitions: pain, physical function (mobility), physical functioning 
(body), QoL, satisfaction, anxiety, depression and patient global assessment. Patient satisfaction was most commonly used $(n=10)$ as single domain with a wide variation in wording of questions and answering categories. The absolute cut-off value was the most common type of response, with large variety in value and timing of follow-up. Table 1 shows one definition for each combination of domains.

Conclusion: Our review shows that definitions for poor response to TKR are ambiguous. Our findings stress the need for an unambiguous definition of poor response to draw conclusions about the prevalence of poorresponders to TKR across hospitals and countries, and to identify patients at risk.

Abstract THU0461 -Table 1. The table shows one definition for each combination of domains

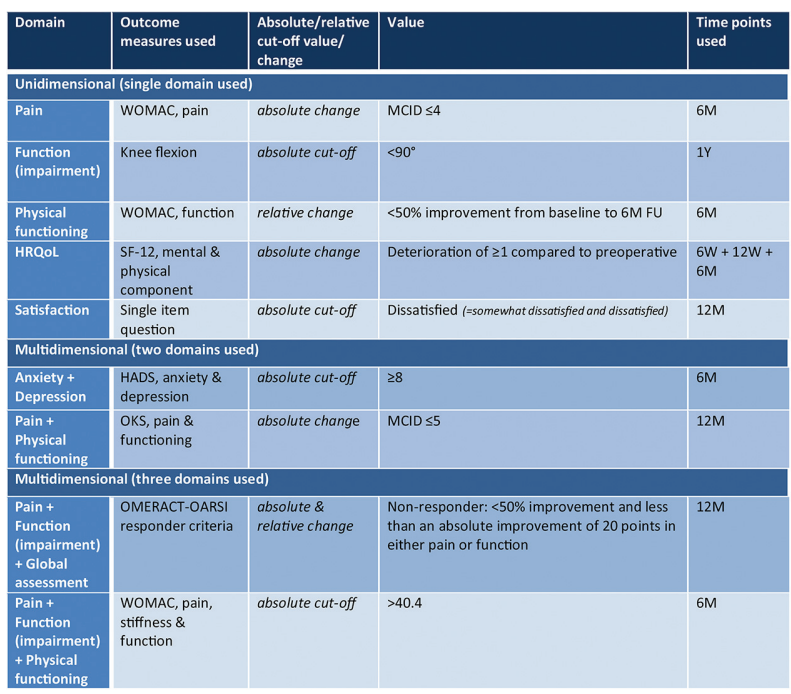

Disclosure of Interests: : None declared

DOI: 10.1136/annrheumdis-2019-eular.7983

\section{THU0462 OUTCOME PREDICTION FOR TREATMENT OF KNEE OSTEOARTHRITIS WITH A TOTAL KNEE ARTHROPLASTY. DEVELOPMENT AND VALIDATION OF A PREDICTION MODEL FOR PAIN AND FUNCTIONAL OUTCOME USING THE DUTCH ARTHROPLASTY REGISTER (LROI) DATA}

J.J. Tolk ${ }^{1}$, J.H. Waarsing ${ }^{2}$, R.P.A. Janssen ${ }^{1}$, L.N. van Steenbergen ${ }^{3}$, S.M. A. Bierma-Zeinstra ${ }^{2,4}$, Max Reijman ${ }^{4}{ }^{1}$ Máxima Medical Centre Eindhoven, Department of orthopaedic surgery and trauma, Eindhoven, Netherlands; ${ }^{2}$ Erasmus MC, University Medical Center Rotterdam, Department of general practice, Rotterdam, Netherlands; ${ }^{3}$ Dutch Arthroplasty Registry, 's Hertogenbosch, Netherlands; ${ }^{4}$ Erasmus MC, University Medical Center Rotterdam, Department of orthopaedic surgery, Rotterdam, Netherlands

Background: One of the main determinants of treatment satisfaction after total knee arthroplasty (TKA) is the fulfilment of preoperative expectations. For optimal expectation management it is useful to be able accurately predict the treatment result. Multiple patient factors that are obtained for registration in the Dutch Arthroplasty Registry (LROI) are associated with the treatment result. Therefore, these factors can potentially be utilised to estimate the most likely outcome on pain and functional outcome for an individual patient

Objectives: The aim of the present study was to create and validate models that predict residual symptoms on 10 specific outcome parameters at 12-month follow-up for patients undergoing primary TKA for knee osteoarthritis.

Methods: Data was extracted from the LROI on TKA patients who had pre- and postoperative PROMs registered in the LROI registry. Multiple logistic regression analyses were performed to construct predictive algorithms for satisfaction, treatment success, and residual symptoms concerning pain in rest and during activity, sit-to-stand movement, stair negotiation, walking, performance of activities of daily living, kneeling and squatting. Models were developed for men and women separately. We assessed predictive performance by examining measures of calibration and discrimination.

Results: Data of 7071 patients could be included for data analysis Residual complaints on kneeling ( $\left.\$ 72 \% / \sigma^{x} 59 \%\right)$ and squatting ( $\$ 71 \% /$ ${ }^{\prime} 56 \%$ ) were reported most frequently, and least residual complaints were scored for walking $\left(\$ 16 \% / \sigma^{x} 12 \%\right)$ and pain in rest ( $\left.18 \% / 0^{x} 14 \%\right)$. The predictive algorithms for residual symptoms concerning sit-to-stand movement, stair negotiation, walking, activities of daily living and treatment success showed acceptable discriminative values (AUC $0.68-0.74$ ). The prediction models for residual complaints regarding kneeling, squatting, pain and satisfaction showed the least favourable results (AUC 0.58 0.64). The calibration curves showed adequate calibration for most of the models.

Conclusion: A considerable proportion of patients has residual complaints after TKA. The present study showed that demographic and PROMs data collected for the LROI registry, can be used to predict the chance for residual symptoms after TKA. The predictive models that have been developed can be useful for individual expectation management in patients planned for TKA for knee osteoarthritis.

Acknowledgement: This study was supported by a grant from the Van Rens Foundation, and conducted with data of the Dutch Arthroplasty Registry.

Disclosure of Interests: None declared

DOI: 10.1136/annrheumdis-2019-eular.1654

\section{THU0463 EXPECTATIONS OF TREATMENT RESULT OF KNEE OSTEOARTHRITIS PATIENTS TREATED WITH A TOTAL KNEE ARTHROPLASTY. THE INFLUENCE OF DEMOGRAPHIC FACTORS, PAIN, PERSONALITY TRAITS, PHYSICAL AND PSYCHOLOGICAL STATUS}

J.J. Tolk ${ }^{1}$, R.P.A. Janssen ${ }^{1}$, T.M. Haanstra ${ }^{2}$, M. (Marieke) C. van der Steen ${ }^{2}$, S.M. A. Bierma-Zeinstra ${ }^{3,4}$, Max Reijman ${ }^{4} .^{1}$ Máxima Medical Center, Department of Orthopedic Surgery and Trauma, Eindhoven, Netherlands, ${ }^{2}$ Radboud University Medical Center, Department of Orthopaedic Surgery, Nijmegen, Netherlands ${ }^{3}$ Erasmus MC, University Medical Center Rotterdam, Department of General Practice, Rotterdam, Netherlands; ${ }^{4}$ Erasmus MC, University Medical Center Rotterdam, Department of Orthopedic Surgery, Rotterdam, Netherlands

Background: Unrealistic preoperative expectations have a strong influence on the outcome after total knee arthroplasty (TKA). More insight into determinants of the level of expectations is useful in identifying patients at risk for unrealistic expectations. This information can be used in optimizing pre-operative expectation management.

Objectives: The aim of the current study was to analyze to what extent pre-operative outcome expectations of TKA patients are determined by psychological factors, demographic factors, pain, physical function and general health status.

Methods: A cross-sectional analysis of 204 patients with symptomatic and radiographic knee OA, scheduled for primary TKA was conducted. Outcome expectations were measured using the Hospital for Special Surgery knee replacement expectations survey. Independent variables included were age, sex, body mass index and patient reported outcome measures for pain, physical function, quality of life, anxiety, depression, catastrophizing, optimism and pessimism. Multiple linear regression analyses were used to evaluate associations between these variables and pre-operative outcome expectations

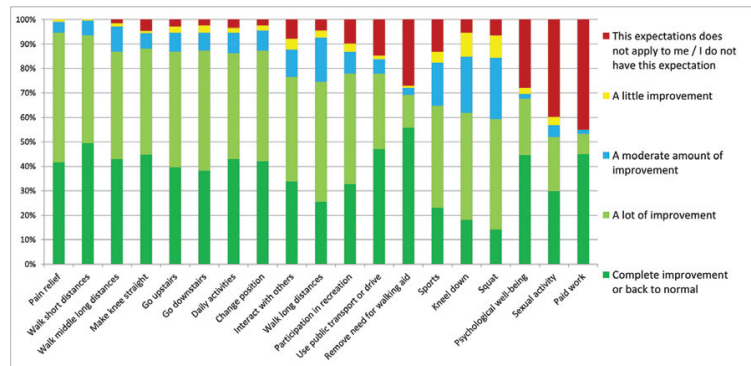

Abstract THU0463 - Figure 1

Results: The mean overall survey score on the HSS-KRES was 70.9 (SD 17.9). Distribution of expectation scores is shown in Figure 1. 